\title{
O saber etnobotânico dos agricultores/as familiares associado a plantas medicinais e suas aplicações, Rolim de Moura/RO, Brasil
}

O objetivo da pesquisa foi analisar o saber etnobotânico dos agricultores/as familiares associados às plantas medicinais no município de Rolim de Moura/RO. Foram coletadas informações de 30 produtores selecionados pela metodologia bola de neve. Utilizou-se o Fator de Consenso do Informante (FCI) e foram classificados os nomes das espécies por meio das famílias botânicas, suas indicações de acordo com a Classificação Estatística Internacional de Doenças e Problemas Relacionados à Saúde (CID-10), Nível de Fidelidade (FL) e Importância Relativa (IR). Foram citadas 136 espécies de plantas medicinais, distribuídas em 56 famílias As plantas tiveram 901 citações e destas foi possível a identificação de 134 espécies, destacando-se as seguintes famílias: Asteraceae (20 espécies), Lamiaceae (17 espécies) e Fabaceae (7 espécies). As de maior número de citação foram Curcuma Longa L. (Açafrão), Mentha sp. (Hortelã), Cyimbopogon citratus Stapf. (Capim Cidreira) e Plectranthus barbatus Andrews (Boldo). Em relação ao $\mathrm{FCl}$, as categorias com maiores valores foram: transtornos do sistema respiratório ( $\mathrm{FCl}=0,70)$ e transtornos do sistema digestório $(\mathrm{FCl}=0,69)$. As que apresentaram valores de IR $>1$ foram: Curcuma Longa $\mathrm{L}$. (Açafrão - IR=2,0) e Plantago major $\mathrm{L}$. (Tanchagem $I R=1,64)$. Aos resultados de $\mathrm{FL}$, destacaram-se as seguintes espécies: Pereskia grandifolia (Ora-pro-nobis $-\mathrm{FL}=80 \%$ ), Sambucus australis, Malpighia glabra Linn Phyllanthus niruri L., Petroselium crispum (Mill.) A. W. Hill, (Sabugueiro, Acerola, Quebra-pedra e Salsa - FL=66,67\%) respectivamente. As folhas foram as partes da planta mais utilizadas $(64,2 \%)$, sendo a infusão/chá $(67,5 \%)$ o procedimento mais comum usado para preparar remédios caseiros. Conclui-se que este trabalho possibilitou maior compreensão acerca da origem dos saberes e das práticas sobre o uso terapêutico das plantas medicinais que além da constatação do uso destas plantas, elas assumem grande valor na vida destes produtores rurais.

\section{The ethnobotanic knowledge of farmers associated with medical plants and their applications, Rolim of Moura/RO, Brazil}

The objective of this research was to analyze the ethnobotanical knowledge of family farmers associated with medicinal plants in the municipality of Rolim de Moura/RO. Information was collected from 30 producers selected by the snowball methodology. The Informant Consensus Factor (FCl) was used and species names were classified by botanical families, their indications according to the International Statistical Classification of Diseases and Related Health Problems (ICD10), Loyalty Level (FL) and Relative Importance (IR). 136 species of medicinal plants were cited, distributed in 56 families. The plants had 901 citations and from these it was possible to identify 134 species, highlighting the following families: Asteraceae ( 20 species), Lamiaceae (17 species) and Fabaceae ( 7 species). The most cited were Curcuma Longa L. (Saffron), Mentha sp. (Mint), Cyimbopogon citratus Stapf. (Lemongrass Grass) and Plectranthus barbatus Andrews (Boldo). Regarding the $\mathrm{FCl}$, the categories with the highest values were: respiratory system disorders $(\mathrm{FCl}=0.70)$ and digestive system disorders $(\mathrm{FCl}=0.69)$. Those with $\mathrm{IR}$ values> 1 were: Curcuma Longa L. (Saffron - IR = 2.0) and Plantago major L. (Plantain - IR = 1.64). The results of FL showed the following species: Pereskia grandifolia (Orapro-nobis - $\mathrm{FL}=80 \%$ ), Sambucus australis, Malpighia glabra Linn, Phyllanthus niruri L., Petroselium crispum (Mill.) A. W. Hill, (Elderberry). Acerola, Rock Breaker and Salsa $-\mathrm{FL}=66.67 \%)$ respectively. The leaves were the most used parts of the plant $(64.2 \%)$, with infusion/tea (67.5\%) being the most common procedure used to prepare home remedies. It is concluded that this work allowed a greater understanding about the origin of knowledge and practices on the therapeutic use of medicinal plants that besides the use of these plants, they assume great value in the life of these farmers.

Keywords: Farmers; Home Remedies; Infusion/Tea.

Topic: Desenvolvimento, Sustentabilidade e Meio Ambiente

Reviewed anonymously in the process of blind peer

Marcelo Santos Lopes (iD)

Universidade Federal de Rondônia, Brasil http://lattes.cnpq.br/2256945022701089 http://orcid.org/0000-0003-4052-1276

marcelosantos@emater-ro.com.br

Sylviane Beck Ribeiro (iD)

Universidade Federal de Rondônia, Brasil http://lattes.cnpq.br/2016815360741068 http://orcid.org/0000-0003-4882-8213

sylvianebeck@unir.br

Gilmara Yoshihara Franco (iD)

Universidade Federal de Rondônia, Brasil http://lattes.cnpq.br/1914393246460112

http://orcid.org/0000-0001-6094-9283

gilmara.franco@unir.br

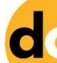

DOI: 10.6008/CBPC2179-6858.2020.005.0040
Received: 10/08/2020 Approved: 21/09/2020

Kenia Michele de Quadros Tronco (iD) Universidade Federal de Rondônia, Brasil http://lattes.cnpq.br/2209314957208420 http://orcid.org/0000-0003-0873-9582

kenia.tronco@unir.br
Referencing this:

LOPES, M. S.; RIBEIRO, S. B.; FRANCO, G. Y.; QUADROS, K. M.. O saber etnobotânico dos agricultores/as familiares associado a plantas medicinais e suas aplicações, Rolim de Moura/RO, Brasil. Revista Ibero Americana de Ciências Ambientais, v.11, n.5, p.437-450, 2020. DOI: http://doi.org/10.6008/CBPC2179-6858.2020.005.0040 


\section{INTRODUÇÃO}

O saber sobre o poder de cura por meio de plantas retomasse desde o aparecimento da espécie humana aqui na Terra. Pois, desde o primórdio as civilizações iniciais observavam que algumas plantas apresentavam substâncias, conhecidas como princípios ativos, os quais ao serem colocados em experimentação combatiam algumas doenças. O Brasil é detentor de rica diversidade cultural e étnica que resultou em um acúmulo considerável de conhecimentos passados de geração a geração dentre os quais se destaca o conhecimento sobre o manejo e uso de plantas medicinais, especialmente na Amazônia (BRASIL, 2006).

A riqueza de saberes a respeito da biodiversidade vegetal serve como base não somente para a descoberta de outras espécies vegetais a serem pesquisadas com finalidades terapêuticas, mas também para o entendimento da própria humanidade. O percurso histórico empírico no tratamento de doenças com plantas e as diferenças na cultura e formas diversas de interpretar, explicar e tratar a doença relacionando com o ambiente natural contribui para entender o próprio homem (OLIVEIRA, 2010).

O conhecimento sobre plantas com finalidades terapêuticas simboliza muitas vezes o único recurso terapêutico de muitas comunidades e grupos étnicos. Ainda hoje nas regiões mais pobres do país e até mesmo nas grandes cidades brasileiras, plantas medicinais são comercializadas em feiras livres, mercados populares e encontradas em quintais residenciais (MACIEL et al., 2002).

Sendo assim, a preservação e o levantamento deste conhecimento, de suas técnicas terapêuticas e aplicações são uma maneira de deixar registrado um modo de aprendizado informal que contribui para a valorização da medicina popular, além de gerar informações sobre as espécies utilizadas, as formas de uso e uma possibilidade enorme de identificar plantas que apresentam potencial para serem pesquisadas e futuramente transformar-se em medicamentos.

As discussões promovidas pelos extensionistas da Emater/RO, tanto no âmbito técnico e social, mas também na área ambiental e do atendimento no dia a dia das famílias rurais aqui no Estado de Rondônia e até fora dele, nos proporciona uma gama de informações para um entendimento maior e das mais variadas particularidades do saber e fazer dos agricultores familiares que habitam e interagem com a nossa região conhecida como Zona da Mata.

Aliado a estas experiências e as diversas áreas de estudos, podemos compreender melhor as ciências interdisciplinares, a antropologia, por exemplo, da qual se originou as chamadas etnociências. Em meio a elas, destaca-se a etnobotânica. Segundo Leão et al. (2007) este associa o conhecimento tradicional, saber local, com a biodiversidade do ambiente. Entre os elementos que constituem essa biodiversidade, estão as plantas medicinais que são utilizadas em comunidades tradicionais, como remédios caseiros, sendo consideradas a matéria-prima para fabricação de fitoterápicos e outros medicamentos.

A agricultura familiar apresenta traços culturais relativos a um processo marcado pela colonização que historicamente deve ser preservado e pesquisado. Para entender melhor como se deu este processo de colonização do Estado de Rondônia, sendo sua população segundo Santos (2014) uma das mais diversificadas 
do Brasil, composta de migrantes oriundos de todas as regiões do país, dentre os quais se destacam os nordestinos, paranaenses, paulistas, mineiros, gaúchos, capixabas, cearenses, baianos além de amazonenses e acreanos, sem esquecer é claro das populações indígenas que aqui já habitavam. Em se tratando de número de propriedades apresenta no total, 111.898,00 (Cento e onze mil e oitocentos e noventa e oito produtores familiares (SEAGRI, 2018). Estudos sobre o público da agricultura familiar ainda são poucos aqui no estado, inclusive trabalhos relacionados a etnobotânica.

A relação entre os entes familiares e o meio ambiente faz com que a Agricultura Familiar seja um público importantíssimo para socializar informações sobre o conhecimento de plantas medicinais e suas aplicações. Portanto, considerando os aspectos apresentados, a proposição desta pesquisa é realizar uma análise sobre o saber etnobotânico, de agricultores/as familiares, associado a plantas medicinais e suas aplicações no município de Rolim de Moura, Rondônia. Assim, essas experiências e informações sobre os recursos terapêuticos das plantas encontradas em seu ambiente natural e/ou antropizado, pode ser um instrumento importante na elaboração de novos medicamentos além da valoração da cultura, das tradições dessas famílias e resgate do saber popular sobre o uso de plantas.

\section{MATERIAIS E MÉTODOS}

\section{Área de estudo, localização e caracterização da pesquisa}

O estudo foi realizado com agricultores familiares residentes no município de Rolim de Moura Rondônia, município este conhecido como ‘Capital da Zona da Mata’ (Figura 1).

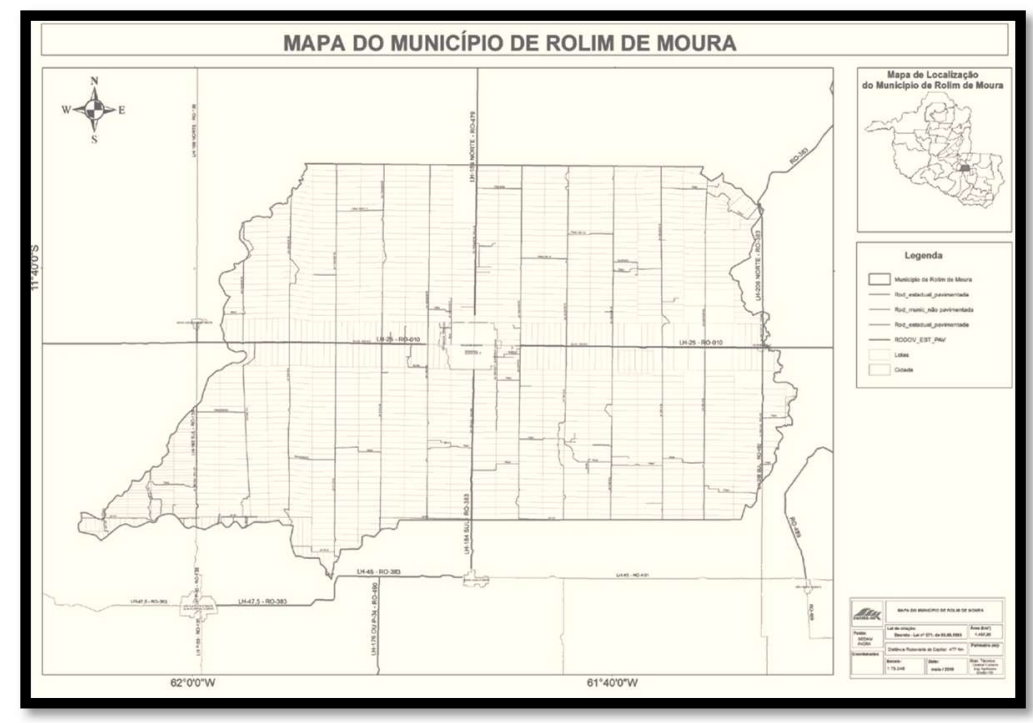

Figura 1: Mapa do município de Rolim de Moura/RO.

O município de Rolim de Moura possui uma população de 54.702 habitantes, numa área territorial de $1.457,888 \mathrm{~km} 2$, sendo sua origem consequência da implantação da extensão do Projeto Integrado de Colonização GY Paraná, que distribuiu lotes de terras rurais a milhares de famílias (IBGE, 2018). Atualmente o município está estruturado administrativamente da seguinte forma: Rolim de Moura, sede municipal e Nova Estrela de Rondônia o único distrito, situado na linha 208 a 25 km da sede do município. O Município 
faz limite com Castanheiras ao Norte, Santa Luzia D'Oeste e Alta Floresta D'Oeste ao Sul, Pimenta Bueno, São Felipe e Cacoal a Leste, Novo Horizonte D’Oeste a Nordeste e está coberto na Região Centro-Sul do Estado, com uma altitude média de 260 metros.

O meio rural rolimourense é traçado por estradas vicinais paralelas numeradas onde são chamadas na região de 'linhas'. A distância entre uma linha e outra é em média $4 \mathrm{~km}$. O Município apresenta uma malha viária de $292 \mathrm{Km}$ de linhas vicinais, sendo atravessado no sentido Norte-Sul pela RO 479, conhecida como Linha 184 e pela RO 010, conhecida como Linha 25. O levantamento das informações acerca do conhecimento sobre plantas medicinais por intermédio dos agricultores familiares foi realizado em onze linhas vicinais.

\section{Aspectos éticos da pesquisa e Coletas das Informações}

A autorização da pesquisa foi concedida pelo Comitê de Ética em Pesquisa em Seres Humanos (CEP) da Universidade Federal de Rondônia (UNIR), conforme relatoria datada de 27 de fevereiro de 2018, Parecer no 2.515.781. Na primeira visita realizada, às residências dos agricultores familiares que participaram da pesquisa, o pesquisador acompanhado de uma extensionista social, a qual fazia uma apresentação da família com um diálogo sobre o dia a dia para 'quebrar o gelo'. Logo em seguida o pesquisador apresentava os objetivos da pesquisa, as questões éticas, e que seria garantido a participação livre e voluntária, assim o pesquisador solicitava, de forma transparente e simples, ao informante, a assinatura do Termo de Consentimento Livre Esclarecido (TCLE). Além disso, ele poderia, a qualquer momento, desistir de participar sem qualquer prejuízo.

\section{Desenvolvimento da Pesquisa de Campo}

Os agricultores familiares indicados para as entrevistas foram selecionados por meio de amostra não probabilística de seleção racional (ALBUQUERQUE et al., 2004), na qual um grupo específico é escolhido. Dentro do grupo a ser pesquisado uma ampliação da amostra foi feita utilizando-se o método "bola de neve", em que um informante indica uma ou mais pessoas que ele acredita ser dotado de experiência no assunto abordado.

A seleção dos informantes partiu do apoio de alguns Presidentes de Associações das Linhas, assim como agentes comunitários de saúde, lideranças do movimento sindical dos trabalhadores e trabalhadoras rurais do município (STTR), bem como, conselheiros do Conselho Municipal de Desenvolvimento Rural Sustentável - CMDRS e auxílio das extensionistas sociais da Emater Local de Rolim de Moura.

As informações sobre as plantas medicinais foram coletadas por meio de entrevistas semiestruturadas e listas livres (ALBUQUERQUE et al., 2014), dentre as quais foram obtidas informações sobre as espécies, suas indicações de uso, partes utilizadas e formas de preparo. A lista livre/formulário foi aplicada por ser uma metodologia versátil que permite acesso às informações sobre o conhecimento etnobotânico (ALBUQUERQUE et al., 2014). Em seguida, foi empregado o método da turnê-guiada, que permitiu a identificação, registro fotográfico individual de cada espécie para identificação taxonômica 
(ALBUQUERQUE et al., 2014), além de ampliar a citação de novas espécies à lista, pelo estímulo ao contato visual. A coleta de dados ocorreu no período de junho de 2018 a novembro de 2018. As entrevistas foram guiadas por um formulário, contendo perguntas abertas e fechadas, um diário de campo, gravador de voz e a observação das plantas com registro fotográfico e seu georreferenciamento (mediante autorização prévia dos entrevistados), bem como fontes secundárias de informações.

Os informantes foram entrevistados individualmente, como recomendado por Phillips et al. (1993), visando evitar que as respostas fossem influenciadas por outro informante. Na maioria dos casos, a entrevista ocorreu no quintal da casa do entrevistado, por iniciativa dele em mostrar as espécies medicinais que tinha.

\section{Técnicas quantitativas para análise de dados etnobiológicos}

A sistematização e análise dos dados da pesquisa foram baseadas na metodologia proposta por Bardin (2002), onde os dados foram analisados quali-quantitativamente e trabalhados por meio das técnicas utilizadas por Albuquerque et al. (2010). As espécies botânicas mencionadas durante a coleta de dados foram organizadas e registradas em tabelas, de acordo com a sua utilização e, posteriormente identificadas.

As doenças citadas nas entrevistas, foram agrupadas segundo a distribuição das categorias de doenças proposta pela Classificação Estatística Internacional de Doenças e Problemas Relacionados à Saúde (CID), 10ạ Revisão (OMS, 2008). Para análise dos dados etnobiológicos foram utilizados os índices de Nível de Fidelidade (FL), Importância Relativa (IR) e o Fator de Consenso do Informante (FCI).

O Fator de Consenso do Informante (FCI), proposto por Troter et al. (1986), aborda que a esta técnica busca identificar as indicações terapêuticas que apresentam a maior importância relativa local, e que agrupam doenças relacionadas com diversos sistemas. Para tanto, é utilizada a seguinte fórmula:

$$
F C I=\frac{\left(n_{u r}-n_{t}\right)}{\left(n_{u r}-1\right)}
$$

Onde: $\mathrm{FCl}$ = fator de consenso do informante; nur = o número de citações de usos em cada sub-categoria; e, nt = número de espécies usadas nesta sub-categoria.

O valor máximo que uma subcategoria pode atingir é 1. Quanto mais próximo deste valor, maior a concordância entre os informantes sobre o uso das espécies nas diferentes sub-categorias.

O Nível de Fidelidade (NF), proposto por Friedman et al. (1986), é uma técnica que tem como objetivo a concordância entre os resultados obtidos dos informantes em cada indicação terapêutica. Sendo que:

$$
F L=\left(\begin{array}{lll}
\text { Ipxlu } & ) & x \\
100 & \%
\end{array}\right.
$$

Onde: $\mathrm{FL}$ = Nível de Fidelidade; $I \mathrm{p}$ = número de informantes que citaram o uso da espécie principal; e, lu = número total de informantes que citaram a espécie para qualquer finalidade.

A Importância Relativa (IR), baseada na técnica proposta por Bennett et al. (2000), simples e fácil de usar, utilizada no estudo de plantas medicinais, cujo avalia qual a planta mais importante, dependendo do quanto é versátil. Para o resultado após as coletas das informações, utiliza-se a seguinte fórmula:

$$
I R=N C S+N P
$$

Onde: IR = Importância Relativa; NCS = número de sistemas corporais; NP = número de propriedades medicinais. 


\section{RESULTADOS E DISCUSSÃO}

\section{Caracterização dos Informantes da Agricultura Familiar de Rolim de Moura}

A agricultura familiar do município de Rolim de Moura, compreende aqueles que trabalham com agricultura, pecuária, piscicultura, fruticultura que em suas propriedades rurais produzem para seu sustento e manutenção da família. A mão de obra é predominante a familiar, salvo algumas exceções que contratam esporadicamente diaristas e que também prestam serviços nas comunidades no entorno.

Foi extremamente gratificante realizar este trabalho perante a agricultura familiar, público este que nos permite refletir sobre os modos de produção, sobre a vida no campo, sobre o zelo com a natureza e com as plantas. A abordagem por meio desta pesquisa foi preponderante para que os resultados fossem satisfatórios e alcançados.

Foram entrevistados 30 agricultores familiares sendo, coincidentemente, 15 homens e 15 mulheres com conhecimento sobre o uso de plantas medicinais. Para caracterização do perfil dos informantes, foram obtidas informações socioeconômicas (Tabela 1), como gênero, idade, naturalidade, tempo de moradia na Região da Zona da Mata, nível de escolaridade, nível socioeconômico, profissão/ocupação, etnia, grupo religioso, número de filhos e nupcialidade.

Tabela 1: Informações socioeconômicas dos informantes participantes da pesquisa.

\begin{tabular}{|c|c|c|c|}
\hline Características & Categorias & FA & FR (\%) \\
\hline \multirow[t]{2}{*}{ Sexo } & Feminino & 15 & 50,0 \\
\hline & Masculino & 15 & 50,0 \\
\hline \multirow[t]{3}{*}{ Faixa Etária (Anos) } & $18-39$ anos & 3 & 10,0 \\
\hline & 40-59 anos & 14 & 46,7 \\
\hline & 60-79 anos & 13 & 43,3 \\
\hline \multirow[t]{2}{*}{ Naturalidade } & Zona da Mata & 1 & 3,3 \\
\hline & Outras regiões do Brasil & 29 & 96,7 \\
\hline \multirow[t]{2}{*}{ Tempo de Moradia na Região da Zona da Mata } & 1-5 anos & 3 & 10,0 \\
\hline & $>5$ anos & 27 & 90,0 \\
\hline \multirow[t]{3}{*}{ Escolaridade (Anos de Estudo) } & $<1$ ano & 1 & 3,3 \\
\hline & 1-9 anos & 25 & 83,3 \\
\hline & $>9$ anos & 4 & 13,3 \\
\hline \multirow[t]{2}{*}{ Nível Socioeconômico } & 1-5 salários mínimo & 27 & 90,0 \\
\hline & >5 salários mínimo & 3 & 10,0 \\
\hline \multirow[t]{3}{*}{ Profissão/Ocupação } & Agricultor (a) & 27 & 90,0 \\
\hline & Raizeiro (a) & 1 & 3,3 \\
\hline & Outros & 2 & 6,7 \\
\hline \multirow[t]{3}{*}{ Etnia } & Negro & 9 & 30,0 \\
\hline & Mestiço (a) & 6 & 20,0 \\
\hline & Branca & 15 & 50,0 \\
\hline \multirow[t]{2}{*}{ Grupo Religioso } & Católico & 18 & 60,0 \\
\hline & Evangélico & 12 & 40,0 \\
\hline \multirow[t]{2}{*}{ Número de Filhos } & Não tem filhos & 5 & 16,7 \\
\hline & Tem filhos & 25 & 83,3 \\
\hline \multirow[t]{2}{*}{ Nupcialidade } & Casados & 26 & 86,7 \\
\hline & Não casados & 4 & 13,3 \\
\hline
\end{tabular}

Com relação ao conhecimento sobre as plantas medicinais, as mulheres foram as que mais contribuíram para o desenvolvimento da pesquisa, onde percebe-se que elas possuem um nível maior de conhecimento das espécies medicinais, sendo que duas agricultoras citaram um grande número de plantas correspondendo a 14\% das indicações terapêuticas (126 citações) e outra 19,9\% com (173) indicações 
terapêuticas, além disso são responsáveis pelos afazeres do lar, cuidar da saúde da família e ajudarem na lida da roça com seus familiares.

O trabalho agrícola e pecuário são os que prevalecem e que originam as receitas das famílias, uma ou outra presta serviço de mão de obra para complementação de renda. A renda familiar mensal dos informantes está entre 1 a 5 salários mínimos, sendo que três dos informantes possuem uma renda acima de 5 salários. Isso nos mostra que é possível ter uma vida digna no campo, com qualidade e sustentabilidade. Dados do IBGE (2017) apontam que nos últimos anos em Rondônia algumas regiões pessoas estão procurando o campo para viver, produzir e serem donos do próprio negócio.

Diante dos resultados socioeconômicos foi possível verificar que a maioria dos informantes, $60 \%$ são da religião católica e isso foi diagnosticado que alguns dos informantes eram pessoas ligadas a pastoral da saúde que faziam cursos de florais, homeopatia e utilizam plantas medicinais como base para elaboração de seus remédios caseiros e atendimento ao público em geral.

Quanto a origem dos agricultores familiares entrevistados, 1 (3,3\%), nasceu em Rolim de Moura, um jovem que conseguiu uma terra por meio do crédito fundiário, permanece na terra produzindo e que aprendeu a utilizar as plantas medicinais com os pais a qual trocam informações constantes sobre as plantas. Os demais 29 (96,7\%) dos entrevistados vieram de outras regiões do país em virtude da 'oferta' de terras e oportunidade que aqui foram oferecidas em meados dos anos 70. Essa informação também nos possibilita dizer que trouxeram em suas bagagens plantas medicinais para elaboração de remédios caseiros.

\section{Uso das Plantas Medicinais pela Agricultura Familiar de Rolim de Moura/RO}

Todos os informantes relataram que fazem uso de práticas envolvendo as plantas medicinais com finalidade terapêuticas. Foi possível verificar que $100 \%$ dos informantes afirmam que existem resultados satisfatórios no uso das plantas com propriedades medicinais. Resultados semelhantes foram verificados em pesquisa realizada no Estado de Pernambuco por Teixeira et al. (2006), onde também foi constatado que $100 \%$ das pessoas entrevistadas recorrem às plantas medicinais em casos de doenças com resultados satisfatórios.

Verifica-se que $60 \%$ dos entrevistados alegaram que aprenderam a usar as plantas medicinais com seus familiares principalmente com seus pais, onde resultados semelhantes levantados por Nunes (2016) no distrito de Rolim de Moura do Guaporé (Alta Floresta/RO) também obteve está forte influência. A forma de repasse do saber sobre as plantas medicinais está diretamente relacionada ao conhecimento que seus familiares mais próximos, os pais, detém sobre estas plantas e, isso em alguns estudos como de Vendruscolo et al. (2006), Salgado (2007) relatam sobre a maneira que este saber é demonstrado ao próximo, seja ele, principalmente via oral.

Estudos correspondentes que foram realizados por Schwambach (2007), no Estado do Rio Grande do Sul, município de Teutônia, foi demonstrado que $92,9 \%$ daqueles informantes utilizam as plantas medicinais no seu dia a dia e que o uso terapêutico das espécies, em 74,8\% dos casos, tem relação com o saber repassado por membros da família aos seus sucessores. 
Se por um lado o alto número de espécies introduzidas pelos migrantes contribui com a disseminação e diversificação do componente vegetal no município de Rolim de Moura, por outro, o baixo número de espécies nativas conhecidas e utilizadas por essa população pode ser um indicador de que a maioria destes ainda não estabeleceu uma identidade com as plantas locais. Isto pode ser evidenciado no momento da pesquisa, não porque os informantes fizessem propositalmente, mas que isto pode acarretar a substituição de espécies nativas por exóticas que vieram juntamente com seus costumes e hábitos devido ao valor (simbólico e utilitário) atribuído às espécies pertencentes à essa categoria. Outro aspecto que favorece a manutenção e status de conhecimento apresentado acima é a estreita relação desses migrantes com as suas regiões de origem, reproduzindo-os em quintais rondonienses, situações típicas vividas na infância que replicaram ao chegarem a Rondônia.

As plantas e demais elementos presentes no quintal promovem a ligação do cotidiano desta família com o seu local de origem e contribuem na manutenção de características culturais por intermédio do manejo adotado.

\section{Espécies de Famílias das plantas citadas}

Foram citadas pelos entrevistados 136 espécies de plantas medicinais com finalidade terapêutica, pertencentes a 56 famílias botânicas. Na figura 2, consta a representação das famílias botânicas citadas pelos agricultores familiares de Rolim de Moura. Foram citadas 20 espécies pertencentes à família das Asteraceae, 17 espécies da família Lamiaceae e 7 espécies da família Fabaceae.

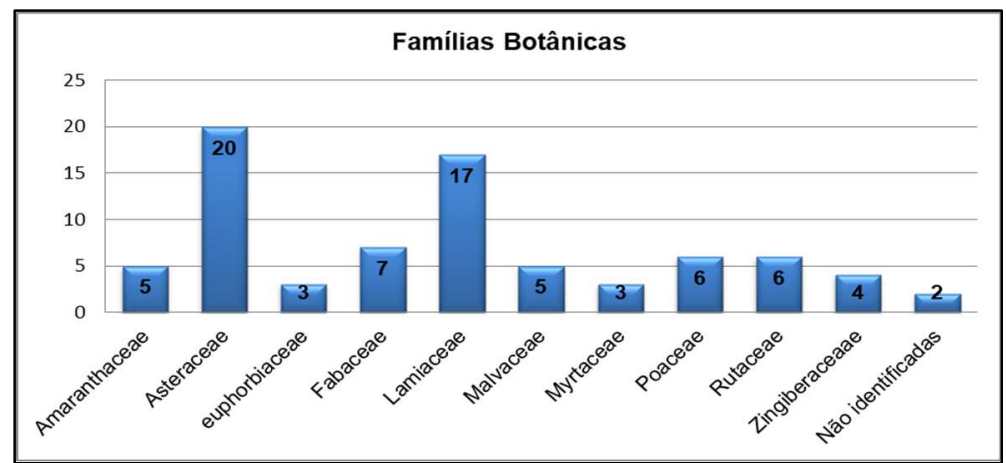

Figura 2: Representação das 56 famílias botânicas mais citadas pelos agricultores familiares do município de Rolim de Moura/RO.

As quatro famílias mais citadas têm sido frequentemente registradas como as mais abundantes em levantamentos da flora medicinal (FERRÃO et al., 2014; PEREIRA et al., 2007) e as mais representativas em outros trabalhos que tem a etnobotânica como referência (KUBO, 1997). Diante desta discussão sobre a predominância da família Asteraceae, Almassy Junior (2004), relata que grande parte das plantas medicinais na América Latina pertence a duas famílias a Lamiaceae e a Asteraceae, logo, elas se caracterizam por possuírem muitas espécies ricas na categoria de princípios ativos, chamados de "óleos essenciais". Essa categoria de princípios ativos responsáveis pelo amplo espectro terapêutico ocorre tanto no sistema digestório quanto no respiratório relata Nunes (2016), visto que foram os sistemas do CID-10 que mais se destacaram nesta pesquisa. 
Segundo Lorenzi et al. (2002) muitas plantas, dessa família, são conhecidas pelas suas propriedades medicinais e diversas espécies possuem atividade analgésica, anti-inflamatória e antimicrobiana comprovadas, além disso, Araújo et al. (2008) relata que podem produzir compostos químicos bastante promissores, sendo estes de grande interesse para a indústria farmacêutica.

Portanto, está representatividade de acordo com Souza et al. (2005) apresenta uma distribuição cosmopolita, ou seja, pode ser encontrada ao redor do mundo, mas apenas dentro de condições que sejam adequadas para sua habitação, sendo que as Asteraceae se adequam melhor em regiões tropicais, subtropicais e temperadas, podendo ocorrer desde o nível do mar até no alto de montanhas. E, as Lamiaceae distribuem-se, principalmente, nas regiões do Mediterrâneo, Oriente e montanhas subtropicais (BARROSO, 1986).

\section{Partes utilizadas das plantas}

Os Agricultores Familiares participantes da pesquisa utilizam, na sua grande maioria, todas as partes das plantas medicinais com finalidades terapêuticas em seus preparos dos medicamentos naturais. Durante a pesquisa as partes mais indicadas das plantas, conforme Figura 3, foram as seguintes: as folhas com $(64,2 \%)$ e a planta inteira com (11\%), sendo as mais representativas com propriedades terapêuticas pelos agricultores.

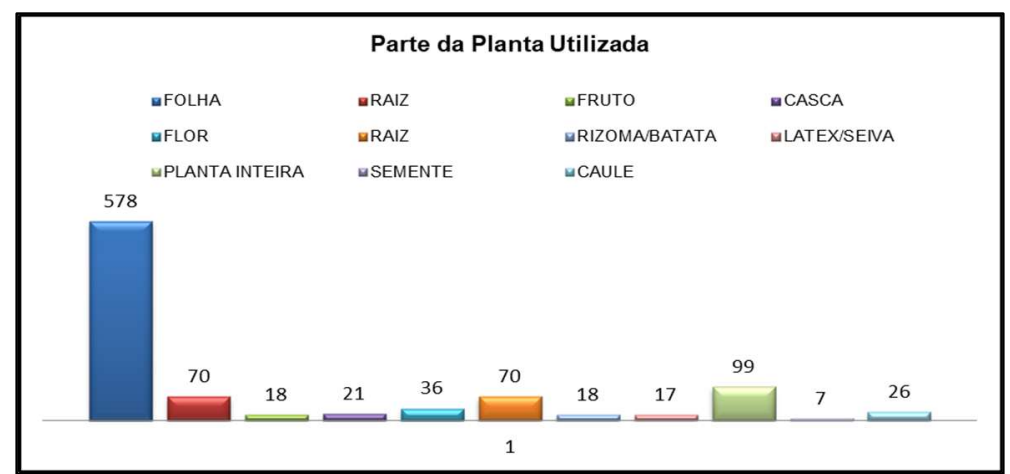

Figura 3: Número de vezes que cada parte das plantas utilizadas foi citada pelos agricultores familiares no município de Rolim de Moura, Rondônia.

A utilização das folhas é explicada por Gonçalves et al. (1998) que isso se deve por ser a parte da planta com maior disponibilidade durante todo o ano e onde encontra-se nesta parte da planta a maior concentração dos princípios ativos para preparação dos medicamentos. Ainda, o uso das folhas implica na conservação do recurso vegetal, por não impedir a reprodução e o desenvolvimento vegetativo e, principalmente, não degradar o sistema reprodutivo da planta (PILLA et al., 2006).

Resultados semelhantes foram obtidos por Meneguelli (2015) e Nunes (2016), que observaram que as partes mais utilizadas foram às folhas por Quilombolas de Pedras Negras-RO e Quilombolas do Distrito de Rolim de Moura do Guaporé-RO, respectivamente, as quais, segundo esses autores, concentram em geral grande parte dos princípios ativos das plantas. Santos et al. (2003) e Nunes (2016) afirmaram a importância do registro das partes das espécies medicinais utilizadas, pois cada órgão pode conter substâncias quimicamente diferentes. 


\section{Forma de preparo das plantas medicinais pelos agricultores familiares de Rolim de Moura/RO}

Os agricultores familiares utilizam as plantas medicinais sob várias formas, sendo que o método por Infusão/Chá se destacou com um total de 67,5\%, totalizando 608 das 901 citações. A importância de se conhecer os aspectos acerca das atividades biológicas do vegetal e sua correta forma de utilização é essencial para a transformação da planta medicinal em medicamento, constituindo, assim, forma útil de tratamento, devido aos seguintes fatores: eficácia e baixo custo financeiro, além da facilidade de adquirir as plantas, que muitas vezes estão presentes nos quintais das próprias residências (FURLAN, 2005).

\section{Dados Etnofarmacológicos}

No estudo o saber etnobotânico da agricultura familiar associado a plantas medicinais e suas aplicações com agricultores familiares de Rolim de Moura/RO, foram obtidas 901 citações de uso para as 136 espécies medicinais citadas, o que equivale a uma média de 6,6 indicações por espécie. Ficou evidenciado uso de plantas medicinais utilizadas para tratamento de enfermidades, sendo estas distribuídas nas categorias do CID-10. Estas foram relacionadas por maior número de espécies citadas conforme figura 4.

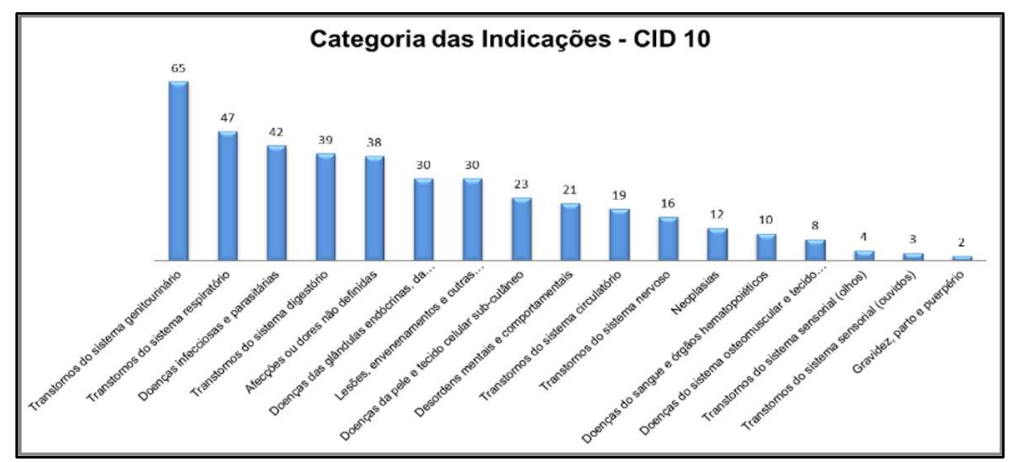

Figura 4: Categoria das Indicações terapêuticas do uso de plantas medicinais pelos agricultores familiares de Rolim de Moura, Rondônia.

As indicações terapêuticas de uso medicinal, tais como doenças do aparelho genitourinário, do sistema respiratório e doenças infecciosas e parasitárias, tiveram destaque sobre o saber local nas categorias de doenças do CID-10. Os transtornos do aparelho genitourinário foi o mais citado no tratamento com as espécies medicinais indicadas, seguidos do transtorno do sistema respiratório e doenças infecciosas e parasitárias.

As citações que fazem parte dos transtornos do Sistema Genitourinário $(47,79 \%)$ apresentaram um total de 65 citações de uso, sendo as de maiores destaques as seguintes: Dor nos rins (40), Diurético (31) e Afecções urinárias (25). Diante destas citações relacionadas a este transtorno de acordo com a Sociedade Brasileira de Nefrologia, no Brasil o número de pacientes com doença renal crônica que precisam de diálise cresceu de 42 mil, em 2000, para 122 mil no ano de 2016, sendo que em Rondônia 1148 fazem diálise (IGBE, 2016). Nesse sentido, Moreira et al. (2003) discutiram que as infecções do trato urinário estão entre as mais comuns de todas as infecções clínicas e, no Brasil, cerca de $80 \%$ das consultas clínicas estão relacionadas às infecções no aparelho urinário. 
A segunda categoria de doença que teve bastante importância foi o Transtorno do Sistema Respiratório (34,55\%) com 47 citações, sendo as de maior relevância as seguintes: Gripe (58), Tosse (29) e Afecções da garganta (19), esses números mostram a quantidade de espécies que podem ser utilizadas para uso medicinal pelos agricultores familiares. De acordo com Castellucci et al. (2000) todas essas doenças apresentam um sintoma em comum que é a obstrução das vias respiratórias, um bom exemplo indicado para essas enfermidades é o gengibre (Zingiber officinale R.), uma das plantas mais citadas para o tratamento destas.

Conforme Meneguelli (2015), resultados semelhantes demonstraram que em sua pesquisa houve um índice alto de citações relacionadas a doenças do sistema respiratório, sendo dessa forma problemas que acometem produtores do meio rural, e que a prática da utilização das plantas medicinais é comum e mostrase eficiente para a cura destas enfermidades corriqueiras. Além disso, ficou evidenciado, mesmo que não relatado, o efeito nocivo causado por aplicar agrotóxicos, utilizando ou não os equipamentos de proteção individual, onde podemos verificar que uma das principais vias de intoxicação é por meio das vias respiratórias.

E a terceira categoria foi o de Doenças Infecciosas e parasitárias (30,88\%) com 42 citações de plantas medicinais relacionada com as doenças mencionadas pelos entrevistados, sendo as de maior relevância as seguintes: Infecções em geral (31) e Verminose (29) números estes que demonstram a importância do saber local e a diversidade de espécies com poder de cura. Corroborando com estes resultados, Nunes (2016), encontrou resultados parecidos, fato este que pode estar relacionado com a qualidade da água ingerida e disponível na propriedade, além disso, plantas com potencial para cura de verminoses e infecções foram citadas tais como Hortelã (Mentha piperita L.), Gervão (Stachytarpheta cayennensis (Rich.) Vahl) e Erva Santa Maria (Chenopodium ambrosioides L.). Com relação aos resultados dos dados Etnobiológicos a categoria com maior valor de consenso do informante foi transtornos do sistema respiratório, com $\mathrm{FCl}=0,7$ (Tabela 2).

Tabela 2: Espécies citadas conforme suas indicações terapêuticas. Onde: $\mathrm{CID} 10$ = Código Internacional da Doença; NE = Número de Espécies; $\mathrm{M}=$ Morfoespécie; TE = Total de Espécie; $\mathrm{CU}=$ Citação de Uso; $\mathrm{FCl}=$ Fator de Consenso do Informante; e, CGE = Citação Geral da Espécie.

\begin{tabular}{|c|c|c|c|c|c|c|c|}
\hline Categoria da doença & $\begin{array}{l}\mathbf{N} \\
\mathbf{E}\end{array}$ & Morfoespécie & Espécie & $\begin{array}{l}\text { T. } \\
\text { E\% }\end{array}$ & CU & $\mathrm{FCl}$ & CGE \\
\hline \multirow[t]{2}{*}{ Transtorno do Sistema Genitourinário } & \multirow[t]{2}{*}{65} & Abacate & Persea americana Mill. & \multirow[t]{2}{*}{48,1} & 10 & 0,5 & 15 \\
\hline & & Canjiru & Arrebidaea chica Verlot & & 10 & 0,5 & 18 \\
\hline Transtorno do Sistema Respiratório & 47 & Gengibre & Zingiber officinale $R$. & 34,8 & 20 & 0,7 & 26 \\
\hline Doenças infecciosas e parasitárias & 42 & Hortelã & Menta Sp. & 31,1 & 8 & 0,3 & 30 \\
\hline Transtornos do sistema digestório & 39 & Boldo & $\begin{array}{l}\text { Plectranthus barbatus } \\
\text { Andrews }\end{array}$ & 28,8 & 22 & 0,6 & 29 \\
\hline Afecções ou dores não definidas & 38 & Açafrão & Curcuma longa $L$. & 28,1 & 8 & 0,5 & 36 \\
\hline $\begin{array}{l}\text { Lesões, envenenamentos e outras consequências } \\
\text { de causas externas }\end{array}$ & 30 & Babosa & Aloe vera Burm. $F$. & 22,2 & 6 & 0,4 & 15 \\
\hline $\begin{array}{l}\text { Doenças das glândulas endócrinas, da nutrição e } \\
\text { do metabolismo }\end{array}$ & 30 & Ora Pra Nobis & Pereskia grandifolia & 22,2 & 4 & 0,3 & 5 \\
\hline \multirow[t]{2}{*}{ Doenças da pele e tecido celular subcutâneo } & \multirow[t]{2}{*}{22} & Alfazema & $\begin{array}{l}\text { Lavandula officinalis } \\
\text { Chaix \& Kitt }\end{array}$ & \multirow[t]{2}{*}{16,4} & \multirow[t]{2}{*}{4} & \multirow[t]{2}{*}{0,4} & 15 \\
\hline & & Confrei & Symphytum officinale L. & & & & 11 \\
\hline Desordens mentais e comportamentais & 21 & Erva Cidreira & Melissa officinalis $L$ & 15,5 & 10 & 0,6 & 23 \\
\hline Transtornos do sistema circulatório & 19 & $\begin{array}{l}\text { Capim } \\
\text { Cidreira } \\
\end{array}$ & $\begin{array}{l}\text { Cyimbopogon citratus } \\
\text { Stapf. }\end{array}$ & 14 & 6 & 0,5 & 29 \\
\hline
\end{tabular}




\begin{tabular}{|c|c|c|c|c|c|c|c|}
\hline \multirow[t]{2}{*}{ Transtornos do sistema nervoso } & \multirow[t]{2}{*}{16} & Arruda & Ruta graveolens & \multirow[t]{2}{*}{11,8} & \multirow[t]{2}{*}{7} & \multirow[t]{2}{*}{0.5} & \multirow{2}{*}{$\frac{14}{29}$} \\
\hline & & $\begin{array}{l}\text { Capim } \\
\text { Cidreira }\end{array}$ & $\begin{array}{l}\text { Cyimbopogon citratus } \\
\text { Stapf. }\end{array}$ & & & & \\
\hline \multirow[t]{2}{*}{ Neoplasias } & \multirow[t]{2}{*}{12} & Babosa & Aloe vera Burm. F. & \multirow[t]{2}{*}{8,8} & \multirow[t]{2}{*}{3} & \multirow[t]{2}{*}{0,6} & 16 \\
\hline & & Graviola & Annona muricata $L$. & & & & 11 \\
\hline Doenças do sangue e órgãos hematopoiéticos & 10 & Açafrão & Curcuma longa $L$. & 7,4 & 5 & 0,4 & 36 \\
\hline $\begin{array}{l}\text { Doenças do sistema osteomuscular e tecido } \\
\text { conjuntivo }\end{array}$ & 8 & Azeduária & Curcuma zedoaria & 5,9 & 3 & 0,3 & 11 \\
\hline \multirow[t]{2}{*}{ Transtornos do sistema sensorial (olhos) } & \multirow[t]{2}{*}{4} & Alfavaca & Ocimum basilicum & \multirow[t]{2}{*}{2,9} & \multirow[t]{2}{*}{3} & \multirow[t]{2}{*}{0,4} & 17 \\
\hline & & Tanchagem & Plantago major $L$. & & & & 25 \\
\hline Transtornos do sistema sensorial (ouvidos) & 3 & Arruda & Ruta graveolens & 2,2 & 2 & 0,3 & 14 \\
\hline \multirow[t]{2}{*}{ Gravidez, parto e puerpério } & \multirow[t]{2}{*}{2} & Arruda & Ruta graveolens & \multirow[t]{2}{*}{1,4} & \multirow[t]{2}{*}{1} & \multirow[t]{2}{*}{0} & 14 \\
\hline & & Hibisco & Hibiscus L & & & & 3 \\
\hline
\end{tabular}

Dentre as enfermidades tratadas através do uso de plantas medicinais podem-se destacar, principalmente, as doenças do trato respiratório (PILLA et al., 2006). Em seguida, destacam-se as demais citações de plantas medicinais relacionada com as doenças mencionadas pelos entrevistados: transtorno do sistema digestório $(0,69)$; desordens mentais e comportamentais $(0,62)$; neoplasias $(0,62)$; afecções odores não definidas $(0,58)$; transtorno do sistema nervoso $(0,55)$; transtorno do sistema genitourinário $(0,52)$; transtorno do sistema circulatório $(0,50)$; lesões, envenenamento e outras consequências de causas externas $(0,46)$; doenças do sangue e órgãos hematopoléticos $(0,43)$; doenças da pele e do tecido celular subcutâneo $(0,40)$; transtorno do sistema sensorial (olhos) $(0,40)$; doenças infecciosas e parasitárias $(0,37)$; doenças das glândulas endócrinas, nutrição e metabolismo $(0,36)$; transtornos do sistema sensorial (ouvidos) $(0,33)$; e, doenças do sistema osteomuscular e tecido conjuntivo (0,30); gravidez, parto e puerpério apresentaram $\mathrm{FCl}$ $=0$.

Com relação à importância relativa açafrão (Curcuma longa L.) atingiu o valor máximo igual a 2. Este índice nos mostra que entre as espécies citadas como medicinais pelos informantes no município de Rolim de Moura, o açafrão foi a mais versátil entre os agricultores familiares participantes em termos de seu uso, além disso, foi indicado para cura de enfermidades em 10 (dez) sistemas corporais diferentes; Plantago major L. e Mentha sp. também apresentaram importância elevada, com valores de IR acima de 1,5 (Tabela 3). A maioria das citações para tratamentos com essas plantas medicinais estavam relacionadas às categorias transtornos do sistema geniturinário, doenças infecciosas e parasitárias e afecções ou dores não definidas.

Acerca do Nível de Fidelidade (FL) trazemos alguns destaques para as seguintes espécies: Pereskia grandifolia (Ora-pro-nobis, FL=80\%), Sambucus australis, Malpighia glabra Linn., Phyllanthus niruri L., Petroselium crispum (Mill.) A. W. Hill, (Sabugueiro, Acerola, Quebra-pedra e Salsa, FL=66,67\%) respectivamente e, Cissus sicyoides (Insulina, $\mathrm{FL}=60 \%$ ).

\section{CONCLUSÕES}

A apresentação dos resultados deste trabalho possibilitou a análise sobre o conhecimento popular dos agricultores familiares acerca das plantas medicinais no município de Rolim de Moura no sentido de identificar e analisar os saberes e as práticas sobre o uso terapêutico destas plantas. O conhecimento que estes agricultores familiares relataram sobre as plantas medicinais mostrou diferentes percepções o quanto a utilização de ervas é importante na vida destas pessoas e que por mais que seja simples um tratamento, 
auxilia na cura de enfermidades. Primeiro que, uma se mostra mais associada ao conhecimento adquirido por seus pais, sendo que existe o reconhecimento e identificação de propriedades fitoterápicas e das mais variadas espécies além de compreenderem, de forma surpreendente, a precaução nas formas de preparo com sua respectiva dosagem. Segundo, observa-se que outras formas de utilização das plantas medicinais estão relacionadas à religiosidade, onde alguns informantes nos relataram que aprenderam sobre as plantas medicinais em cursos e trocas de experiências por meio das pastorais de saúde.

\section{REFERÊNCIAS}

ALBUQUERQUE, U. P.; LUCENA, R. F. P.. Métodos e técnicas na pesquisa etnobotânica. Recife: NUPPEA, 2004.

ALBUQUERQUE, U. P.; LUCENA, R. F. P.; CUNHA, L. V. F. C. Métodos e técnicas napesquisa etnobiológica $\mathrm{e}$ etnoecológica. Recife: NUPPEA, 2010.

ALMASSY JÚNIOR, A. A.. Análise das características etnobotânicas e etnofarmacológicas de plantas medicinais na comunidade de Lavras Novas, Ouro Preto, MG. Tese (Doutorado em Fitotecnia) - Universidade Federal de Viçosa, Viçosa, 2004.

ARAÚJO, E. L.; RANDAU, K. P.; SENA-FILHO, J. G.; PIMENTEL, R. M. M.; XAVIER, H. S.. Acanthospermum hispidum DC (Asteraceae): perspectives for a phytotherapeutic product. Revista Brasileira de Farmacognosia, Curitiba, v.18, p.777784, 2008.

BARDIN, L.. Análise de conteúdo. Lisboa: Edições 70, 2002.

BARROSO, G. M.. Sistemática de Angiospermas do Brasil. 3 ed. Viçosa: Imprensa Universitária, 1986.

BRASIL. Ministério da Saúde. Secretaria de Ciência, Tecnologia e Insumos Estratégicos. Departamento de Assistência Farmacêutica. Política nacional de plantas medicinais e fitoterápicos. Brasília: Ministério da Saúde, 2006.

CASTELLUCCI, S.; LIMA, M. I. S.; NORDI, N.; MARQUES, J. G. W.. Plantas medicinais relatadas pela comunidade residente na estação ecológica de Jataí, município de Luís Antônio-SP, uma abordagem etnobotânica. Revista Brasileira de Plantas Medicinais, v.3, n.1, p.51-60, 2000.

OMS. Organização Mundial de Saúde. CID-10: Classificação estatística internacional de doenças e problemas relacionados à saúde. São Paulo: EDUSP, 2008.

DELGADO, G. C.; BERGAMASCO, S. M. P. P.. Agricultura familiar brasileira: desafios e perspectivas de futuro. Brasília: Ministério do Desenvolvimento Agrário, 2017.

FRIEDMAN, J.; YANIV, Z.; DAFNI, A.; PALEWITCH, D.. A preliminary classification of the healing potential of medicinal plants, based on a rational analysis of an ethnopharmacological field survey among Bedouins in the Negev desert, Israel. Journal of Ethnopharmacology, Amsterdan, v.16, p.275-187, 1986.

FURLAN, A. R.. Cultivo de plantas medicinais. 2 ed. Cuiabá: SEBRAE/MT, 2005.
GONÇALVES, M. I. A.; MARTINS, D. T.. Plantas medicinais usadas pela população do município de Santo Antônio de Leveger, Mato Grosso, Brasil. Revista Brasileira

Farmacognosia, Rio de Janeiro, v.79, n.3/4, p.56-61, 1998.

IBGE. Instituto Brasileiro de Geografia e Estatística. Censo Demográfico, 2017.

IBGE. Instituto Brasileiro de Geografia e Estatística. Área da unidade territorial: Área territorial brasileira. Rio de Janeiro: IBGE, 2018.

KUBO, R. R.. Levantamento das plantas de uso medicinal em Coronel Bicado, RS. Dissertação (Mestrado em Botânica) - Universidade Federal do Rio Grande do Sul, Porto Alegre, 1997.

LEÃO, R. B. A.; FERREIRA, M. R. C.; JARDIM, M. A. G.. Levantamento de plantas de uso terapêutico no município de Santa Bárbara do Pará, Estado do Pará, Brasil. Revista Brasileira de Farmácia, v.88, n.1, p.21-25, 2007.

LORENZI, H.; MATOS, F. J. A.. Plantas medicinais no Brasil: nativas e exóticas. 2 ed. Nova Odessa: Instituto Plantarum, 2002.

MACIEL, M. A. M.; PINTO, A. C.; VEIGA JUINOR, V. F.. Plantas medicinais: a necessidade de estudos multidisciplinares. Revista Química Nova, v.23, n.3, p.429-438, 2002. DOI: https://doi.org/10.1590/S0100-40422002000300016

MENEGUELLI, A. Z.. Etnobotânica na Comunidade de Remanescentes de Quilombo de Pedras Negras/RO. Dissertação (Mestrado em Ciências Ambientais) - Fundação Universidade Federal de Rondônia, Porto Velho, 2015.

NUNES, R. O.. Prospecção etnofarmacológica de plantas medicinais utilizadas pela população remanescente de quilombolas de Rolim de Moura do Guaporé, Rondônia, Brasil. Tese (Doutorado em Fitotecnia) - Universidade Federal de Viçosa, Viçosa, 2016.

OLIVEIRA, P. S.. Plantas medicinais numa comunidade rural assentada no município de Cordeiropólis/SP: etnofarmacologia e educação. Dissertação (Mestrado em Biologia) - Universidade Estadual de Campinas, Campinas, 2010.

PEREIRA, Z. V.; GOMES, C. F.; LOBTCHENKO, G.; GOMES, M. E. S.; SIMÕES, P. D. A.; SARUWATARI, R. P. S.; RIGO, V. F.; CORDEIRO, W. P.. Levantamento das plantas medicinais do Cerrado Sensu Stricto da Fazenda Paraíso, Dourados, MS. 
Revistas de Biociências, v.1, p.249-251, 2007.

PILLA, M. A. C.; AMOROZO, M. C. L.; FURLAN, A.. Obtenção e uso das plantas medicinais no distrito de Martim Francisco, Municipio de Mogi-Mirim, SP, Brasil. Acta Botânica Brasilica, Rio de Janeiro, v.20, n.4, p.789-802, 2006.

PHILLIPS, O.; GENTRY, A. M.. The useful plants of Tambopata, Peru. I. Statistical hypothesis with a new quantitative technique. Economic Botany, v.47, n.1, p.15-32, 1993.

RODRIGUES, V. E. G.; CARVALHO, D. A.. Levantamento etnobotânico de plantas medicinais do domínio cerrado na região do Alto Rio Grande, Minas Gerais. Ciência Agrotécnica, v.25, p.102-123, 2001.

SALGADO, C. L.. O conhecimento popular sobre plantas Um estudo etnobotânico em quintais de Martinésia. Monografia (Bacharelado em Ciências Biológicas) Universidade Federal de Uberlândia, Uberlândia, 2007.

SANTOS, L. M.. Ecologia de saberes: a experiência do diálogo entre conhecimento científico e conhecimento tradicional na comunidade quilombola da Rocinha. Tempus, Actas de
Saúde Colet, Brasília, v.8, n.2, p.243-56, 2014.

SCHWAMBACH, K. H.. Utilização de plantas medicinais e medicamentos no autocuidado no município de Teutônia, RS. Dissertação (Mestrado em Ciências Farmaceuticas) Universidade Federal do Rio Grande do Sul, Porto Alegre, 2007.

SOUZA, A. J. A.. Uso de Plantas Medicinais no Município de Benevides/Pará: Elaboração do Memento Fitoterápico e Construção da Política Municipal de Plantas Medicinais e Fitoterápicos. Dissertação (Mestrado Profissional em Gestão dos Recursos Naturas e Desenvolvimento Local na Amazônia) - Universidade Federal do Pará, Belém, 2010.

TEIXEIRA, S. A.; MELO, J. I. M.. Plantas medicinais utilizadas no município de Jupi, Pernambuco, Brasil. Iheringia, v.61, n.1-2, p.5-11, 2006.

VENDRUSCOLO, G. S.; MENTZ, L. A.. Estudo da concordância das citações de uso e importância das espécies e famílias utilizadas como medicinais pela comunidade do bairro Ponta Grossa, Porto Alegre, Rio Grande do Sul, Brasil. Acta Bot. Bras., v.20, p.367-382, 2006. DOI: http://dx.doi.org/10.1590/S0102-33062006000200012

A CBPC - Companhia Brasileira de Produção Científica (CNPJ: 11.221.422/0001-03) detém os direitos materiais desta publicação. Os direitos referem-se à publicação do trabalho em qualquer parte do mundo, incluindo os direitos às renovações, expansões e disseminações da contribuição, bem como outros direitos subsidiários. Todos os trabalhos publicados eletronicamente poderão posteriormente ser publicados em coletâneas impressas sob coordenação da Sustenere Publishing, da Companhia Brasileira de Produção Científica e seus parceiros autorizados. Os (as) autores (as) preservam os direitos autorais, mas não têm permissão para a publicação da contribuição em outro meio, impresso ou digital, em português ou em tradução. 